\title{
Relative Bioavailability Study of an Abuse-Deterrent Formulation of Extended-Release Oxycodone with Sequestered Naltrexone (ALO-02) Versus Immediate-Release Oxycodone Tablets in Healthy Volunteers
}

\author{
Bimal Malhotra $^{1 *}$, Kyle Matschke ${ }^{2}$, Candace Bramson ${ }^{3}$, Qiang Wang ${ }^{3}$ and Joanne Salageanu ${ }^{3}$
}

${ }^{1}$ Pfizer Inc, New York, New York, USA

${ }^{2}$ Pfizer Inc, Collegeville, Pennsylvania, USA

${ }^{3}$ Pfizer Inc, Groton, Connecticut, USA

\begin{abstract}
Background: ALO-02, an opioid formulation intended to deter abuse, comprising capsules filled with pellets of extended-release oxycodone hydrochloride, an opioid, surrounding sequestered naltrexone hydrochloride, an opioid antagonist. This study compared oxycodone pharmacokinetics following ALO-02 (oxycodone/naltrexone $40 \mathrm{mg} / 4.8$ $\mathrm{mg}$ ) versus immediate-release oxycodone (IRO) tablets $(20 \mathrm{mg})$.
\end{abstract}

Methods: This was an institutional review board-approved, open-label, single-dose, randomized, two-way crossover study in 14 healthy fasted adults (aged 18 to 55 years). Plasma concentrations of oxycodone, naltrexone, and 6- $\beta$-naltrexol were determined. Maximum plasma concentration $\left(C_{\max }\right)$, area under the plasma concentrationtime profile from time 0 to infinity $\left(A \cup C_{\text {inf }}\right)$ and to the last quantifiable concentration $\left(A \cup C_{\text {last }}\right)$, time to $C_{\text {max }}\left(T_{\text {max }}\right)$, and terminal half-life $\left(t_{1 / 2}\right)$ were determined. Adverse events (AEs) were recorded throughout the study.

Results: Median oxycodone $T_{\max }$ was prolonged (12 versus 1 hours) and mean $t_{1 / 2}$ was longer $(7.2$ versus 4.6 hours) for ALO-02 versus IRO. ALO-02/IRO ratio ( $90 \%$ confidence interval [CI]) of adjusted geometric means for dose-normalized $A \cup C_{\text {inf }}$ was $107.2 \%(96.7 \%, 118.8 \%)$, with $\mathrm{Cl}$ contained within equivalence limits of $80 \%-125 \%$. Dose-normalized ALO-02/IRO C $\mathrm{C}_{\text {ax }}$ ratio $(90 \% \mathrm{CI})$ was $33.0 \%(28.8 \%, 37.9 \%)$. Following ALO-02 administration, plasma naltrexone concentrations were below the limit of quantification (BLQ; $4.00 \mathrm{pg} / \mathrm{mL}$ ), and 6- $\beta$-naltrexol concentrations were BLQ $(4.00 \mathrm{pg} / \mathrm{mL})$ in $>50 \%$ of participants or generally low $(<50.0 \mathrm{pg} / \mathrm{mL})$. Most AEs were mild, with nausea and dizziness being most frequent.

Conclusion: Pharmacokinetic comparisons indicate equivalent oxycodone bioavailability under fasted conditions. The lower $\mathrm{C}_{\max }$ and longer $\mathrm{T}_{\max }$ and $\mathrm{t}_{1 / 2}$ observed for ALO-02 versus IRO are consistent with the extended-release profile of ALO-02 formulation. Low naltrexone and 6- $\beta$-naltrexol concentrations indicated successful sequestration of naltrexone in ALO-02.

Keywords: Abuse-deterrent formulation; Opioid; Naltrexone; Oxycodone; Extended release; Pharmacokinetics

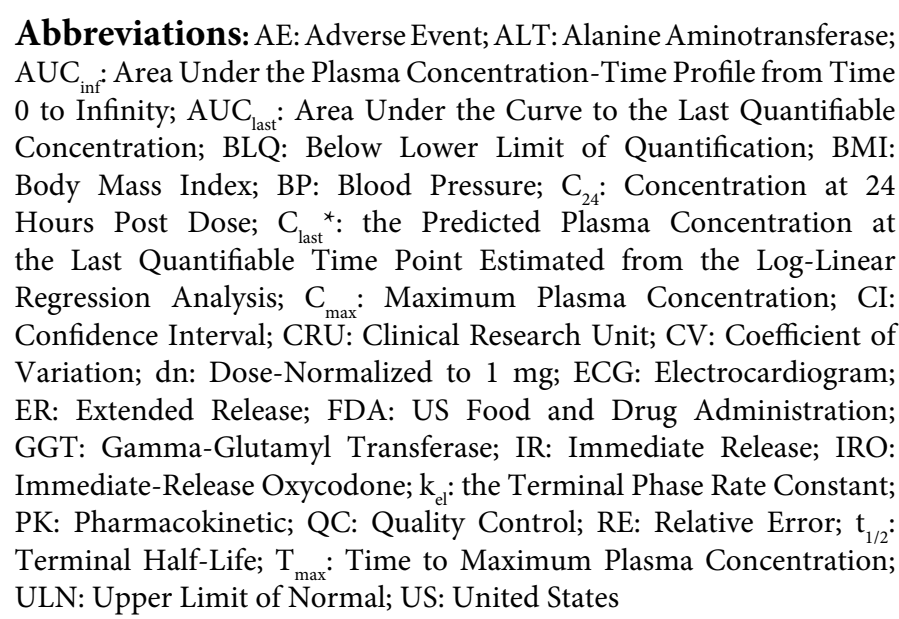

\section{Introduction}

Opioid analgesics are effective medications available to treat acute pain, most notably of surgical origin, and to alleviate chronic pain associated with terminal or non-terminal conditions in carefully selected and monitored patients [1,2]. Extended-release (ER) opioid formulations are indicated for the treatment of pain severe enough to require daily, around-the-clock, long-term treatment for which alternative treatment options are inadequate [3]. ER opioid formulations are taken only once daily or twice daily, compared with every 4- to 6-hour dosing with conventional immediate-release (IR) formulations. However, along with the increased popularity and availability of ER opioid formulations, misuse, abuse, and diversion of these medications has become a significant public health issue in the United States (US) [4-6].

Strategies are therefore needed to address the medical need for pain relief while offering approaches to minimize prescription opioid abuse. One strategy is the development of new drug formulations intended to reduce the attractiveness to abusers and drug-liking qualities of conventional opioid formulations while still providing pain

*Corresponding author: Bimal K Malhotra, Sr. Director, Clinical Pharmacology,
Pfizer Inc, 235 East 42nd Street, New York, NY 10017, USA, Tel: +1(212)733-4723; Fax: +1(646)441-4490; E-mail: bimal.k.malhotra@pfizer.com

Received August 12, 2014; Accepted October 07, 2014; Published November 01,2014

Citation: Malhotra B, Matschke K, Bramson C, Wang Q, Salageanu J (2014) Relative Bioavailability Study of an Abuse-Deterrent Formulation of ExtendedRelease Oxycodone with Sequestered Naltrexone (ALO-02) Versus ImmediateRelease Oxycodone Tablets in Healthy Volunteers. J Bioequiv Availab 6: 186-191. doi:10.4172/jbb.1000202

Copyright: @ 2014 Malhotra B, et al. This is an open-access article distributed under the terms of the Creative Commons Attribution License, which permits unrestricted use, distribution, and reproduction in any medium, provided the original author and source are credited. 
Citation: Malhotra B, Matschke K, Bramson C, Wang Q, Salageanu J (2014) Relative Bioavailability Study of an Abuse-Deterrent Formulation of Extended-Release Oxycodone with Sequestered Naltrexone (ALO-02) Versus Immediate-Release Oxycodone Tablets in Healthy Volunteers. J Bioequiv Availab 6: 186-191. doi:10.4172/jbb.1000202

relief. The US Food and Drug Administration (FDA) is encouraging manufacturers to develop novel opioids that are formulated to deter abuse and considers their development a high public health priority [7].

The four most common routes of administration by which prescription opioids are abused are: oral, intranasal, smoking, and intravenous. The National Addictions Vigilance Intervention and Prevention Program identified that oxycodone formulations were most commonly abused by the oral route, followed by intranasal and intravenous routes [8]. ER prescription opioids may be abused by ingestion of excess amount of pills, or by tampering with the formulation first by chewing or crushing and then smoking or snorting, or crushing and dissolving in various solvents and then injecting [9].

ALO-02, an opioid formulation intended to deter abuse, contains pellets that consist of ER oxycodone hydrochloride $(\mathrm{HCl})$, an opioid agonist, that surrounds sequestered naltrexone $\mathrm{HCl}$, a selective $\mu$-opioid receptor antagonist. ALO-02 is designed to deliver therapeutic doses of oxycodone in a controlled-release manner when the formulation is taken intact as directed; however, when the formulation matrix is tampered with (e.g., by crushing or chewing the pellets), the naltrexone is co-released with oxycodone.

The primary objective of this study was to estimate the relative bioavailability of oxycodone from ALO-02 $40 \mathrm{mg}$ capsules containing $12 \%$ naltrexone $\mathrm{HCl}$ (i.e., ratio of naltrexone $\mathrm{HCl}$ /oxycodone $\mathrm{HCl}$ is $12 \%$ by weight) compared with IR oxycodone (IRO; Roxicodone ${ }^{\circledR}$; Xanodyne, Newport, KY) $20 \mathrm{mg}$ tablets in healthy volunteers. Secondary objectives were to characterize the exposure levels of naltrexone and its primary metabolite 6- $\beta$-naltrexol, following single-dose administration of intact ALO-02 $40 \mathrm{mg}$ capsules, and to evaluate safety and tolerability of oxycodone following single-dose administration of ALO-02 $40 \mathrm{mg}$ capsules and IRO $20 \mathrm{mg}$ tablets in healthy volunteers.

\section{Methods}

\section{Study population}

Men and/or women aged 18 to 55 years were eligible to participate in this study if they were in good health based on a detailed medical history (with no clinically relevant abnormalities), full physical examination, including blood pressure (BP), heart rate measurement, 12-lead electrocardiogram (ECG) and clinical laboratory tests; had a body mass index (BMI) of $17.5-30.5 \mathrm{~kg} / \mathrm{m}^{2}$; and a total body weight $>50 \mathrm{~kg}(110 \mathrm{lb})$. Women could not be pregnant or lactating, and those of childbearing age had to use an acceptable method of contraception from at least 14 days prior to the first dose of study medication and for 28 days after the last dose of study medication. Subjects were excluded if they had a history or a current evidence of clinically significant hematological, renal, endocrine, pulmonary, gastrointestinal, cardiovascular, hepatic, psychiatric, neurologic, or allergic disease (including drug allergies, but excluding untreated, asymptomatic, seasonal allergies at time of dosing); had any severe acute or chronic medical or psychiatric condition or laboratory abnormality that could have increased the risk associated with study participation or investigational product administration or could have interfered with the interpretation of study results; had any condition possibly affecting drug absorption (e.g., gastrectomy); had a history of allergy or hypersensitivity to oxycodone, naltrexone, or any related products; had a positive urine drug screen; had a history of alcoholism or moderate-to-heavy consumption of alcohol, defined as exceeding seven drinks/week for women and 14 drinks/week for men within six months of screening; used tobacco- or nicotine-containing products on average exceeding the equivalent of five cigarettes per day; treated with an investigational drug within 30 days; and if they were unwilling or unable to comply with all components of the study protocol. Additionally, participants were not allowed to use prescription drugs (excluding hormonal therapy for birth control), nonprescription drugs, or dietary supplements within seven days prior to the first dose of study medication. Herbal supplements had to be discontinued at least 28 days prior to the first dose of study medication. As an exception, acetaminophen/paracetamol could have been used at doses of $\leq 1 \mathrm{~g} /$ day. Limited use of nonprescription medications that were not believed to affect participant safety or the overall results of the study could have been permitted on a case-by-case basis.

\section{Study design}

This was an open-label, single-dose, randomized, two-way crossover study (B4531007; ClinicalTrials.gov NCT01677065). This study was conducted at a Pfizer Clinical Research Unit (CRU; New Haven, Connecticut, USA) from September 7, 2012 to October 15, 2012. The final protocol and informed consent documents were reviewed and approved by an institutional review board at Austin, Texas, USA. This study was conducted in compliance with the ethical principles originating in or derived from the Declaration of Helsinki and in compliance with all International Conference on Harmonization Good Clinical Practice Guidelines. In addition, all local regulatory requirements were followed, in particular, those affording greater protection to the safety of trial participants. All participants gave written informed consent prior to entering the study.

The screening visit occurred within 28 days prior to the first dose of Period 1. Enrolled participants were randomly assigned to one of two treatment sequences (ALO-02 followed by IRO or IRO followed by ALO-02). Each participant received the following two treatments under fasted conditions separated by at least a seven-day washout period: 1) ALO-02 $40 \mathrm{mg}$ capsules ( $1 \times 40 \mathrm{mg}$ capsule), and 2) IRO 20 mg tablet $\left(1 \times 15 \mathrm{mg}\right.$ tablet plus $1 \times 5 \mathrm{mg}$ tablet of Roxicodone $\left.{ }^{\circledR}\right)$.

For each treatment period, participants were admitted to the CRU on the day before dosing. On the next morning, following an overnight fast of at least 10 hours, participants received one of the two treatments (ALO-02 or IRO) as a single dose with $240 \mathrm{~mL}$ of ambient temperature water. Participants swallowed the study medication intact, and did not chew the medication prior to swallowing. Blood samples were collected and safety assessments were made at pre-specified times before and after administration of study treatment (detailed below). Participants were discharged from the CRU after the collection of the 48-hour blood sample and returned to the CRU on an outpatient basis for additional analyses as required. Final safety assessment was conducted at the end of Treatment Period 2 or upon earlier withdrawal from the study.

\section{Pharmacokinetic assessments}

Blood samples were drawn during the two treatment periods for pharmacokinetic (PK) analysis of oxycodone, naltrexone, and 6 - $\beta$-naltrexol in plasma. For oxycodone analysis, blood samples were taken at predose (time 0 ) and $0.5,1,2,4,6,8,12,14,16,24,36$, and 48 hours after administration of ALO-02, and at $0,0.25,0.5,1,1.5,2$, $3,4,6,8,12,16,24$, and 48 hours after administration of IRO. For naltrexone and $6 \beta$-naltrexol analysis, blood samples were taken at 0 , $0.5,1,2,4,6,8,12,24,48,72,96$, and 120 hours after administration of ALO-02.

Blood samples $(4 \mathrm{~mL})$ to provide approximately $1.5 \mathrm{~mL}$ plasma 
Citation: Malhotra B, Matschke K, Bramson C, Wang Q, Salageanu J (2014) Relative Bioavailability Study of an Abuse-Deterrent Formulation of Extended-Release Oxycodone with Sequestered Naltrexone (ALO-02) Versus Immediate-Release Oxycodone Tablets in Healthy Volunteers. J Bioequiv Availab 6: 186-191. doi:10.4172/jbb.1000202

for PK analysis of oxycodone and blood samples $(6 \mathrm{~mL})$ to provide approximately $2 \mathrm{~mL}$ plasma for PK analysis of naltrexone and 6 - $\beta$-naltrexol were collected respectively into appropriately labelled tubes containing dipotassium ethylenediamine tetraacetic acid (K $\mathrm{K}_{2}$ EDTA). Blood samples were centrifuged at approximately $1700 \times \mathrm{g}$ for about 10 minutes at $4^{\circ} \mathrm{C}$. The plasma was stored in appropriately labeled screw-capped polypropylene tubes at approximately $-20^{\circ} \mathrm{C} \pm$ $10^{\circ} \mathrm{C}$ within 1 hour of collection.

Plasma samples were analyzed for oxycodone, naltrexone, and 6- $\beta$-naltrexol concentrations at Covance Bioanalytical Services LLC (Indianapolis, Indiana, USA) using a validated, sensitive, and specific high-performance liquid chromatography tandem mass spectrometry (HPLC-MS/MS) method. Calibration standard responses were linear over the range of $0.100-50.0 \mathrm{ng} / \mathrm{mL}$ for oxycodone and over the range of $4.00-2000 \mathrm{pg} / \mathrm{mL}$ for naltrexone and $6-\beta$-naltrexol, using a weighted $\left(\mathrm{l} /\right.$ concentration $\left.^{2}\right)$ linear regression. Those samples with concentrations above the upper limits of quantification were adequately diluted into calibration range prior to analysis. The lower limit of quantification was $0.100 \mathrm{ng} / \mathrm{mL}$ for oxycodone, and $4.00 \mathrm{pg} / \mathrm{mL}$ for both naltrexone and 6- $\beta$-naltrexol. The plasma concentrations below the lower limit of quantification were reported as below lower limit of quantification (BLQ). The concentrations below BLQ were set to 0 for the PK analysis.

The between-day assay accuracy, expressed as percentage relative error (\%RE), for low $(0.30 \mathrm{ng} / \mathrm{mL})$, medium $(3.00 \mathrm{ng} / \mathrm{mL})$, high $(37.5$ $\mathrm{ng} / \mathrm{mL}$ ), and diluted $(250 \mathrm{ng} / \mathrm{mL}$ ) quality control (QC) concentrations, ranged from $3.2 \%$ to $12.7 \%$ for oxycodone. Assay precision, expressed as the between-day percentage coefficient of variation $(\% \mathrm{CV})$ of the estimated concentrations of QC samples, was $\leq 6.9 \%$ for low, medium, high, and diluted QC concentrations of oxycodone.

The between-day assay accuracy expressed as \%RE, for low (12.0 $\mathrm{pg} / \mathrm{mL})$, medium $(20.0 \mathrm{pg} / \mathrm{mL})$, high $(120 \mathrm{pg} / \mathrm{mL})$, and diluted $(1500$ $\mathrm{pg} / \mathrm{mL}$ ) QC concentrations, ranged from $-5.0 \%$ to $0.0 \%$ for naltrexone, and from $-4.0 \%$ to $-0.8 \%$ for $6-\beta$-naltrexol. The assay precision for the low, medium, high, and diluted QC concentrations was $\leq 8.3 \%$ for naltrexone and $\leq 6.4 \%$ for $6-\beta$-naltrexol.

PK parameters for oxycodone, naltrexone, and 6- $\beta$-naltrexol were calculated for each participant and treatment, as applicable, using non-compartmental analysis of concentration-time data, and included maximum plasma concentration $\left(\mathrm{C}_{\max }\right)$, area under the plasma concentration-time profile from time 0 extrapolated to infinity $\left(\mathrm{AUC}_{\text {inf }}\right)$, area under the plasma concentration-time profile from time 0 to the last quantifiable concentration $\left(\mathrm{AUC}_{\text {last }}\right)$, time to $\mathrm{C}_{\max }\left(\mathrm{T}_{\max }\right)$, concentration at 24 hours post dose $\left(\mathrm{C}_{24}\right)$, and terminal half-life $\left(\mathrm{t}_{1 / 2}\right)$. $\mathrm{AUC}_{\text {last }}$ was determined using the linear/log trapezoidal method. $\mathrm{AUC}_{\text {inf }}$ was calculated using the formula $\mathrm{AUC}_{\text {last }}+\left(\mathrm{C}_{\text {last }}{ }^{\star} / \mathrm{k}_{\mathrm{el}}\right)$, where $\mathrm{C}_{\text {last }}{ }^{*}$ was the predicted plasma concentration at the last quantifiable time point estimated from the log-linear regression analysis and $\mathrm{k}_{\mathrm{el}}$ was the terminal phase rate constant. $t_{1 / 2}$ was calculated using the formula $\log _{\mathrm{e}}(2) / \mathrm{k}_{\mathrm{el}}$, where $\mathrm{k}_{\mathrm{el}}$ was the terminal phase rate constant calculated by a linear regression of the log-linear concentration-time curve. Only those data points judged to describe the terminal log-linear decline were used in the regression. Dose-normalized (dn) $\mathrm{AUC}_{\text {last }}, \mathrm{AUC}_{\mathrm{inf}}$, and $\mathrm{C}_{\max }$ were also determined. $\mathrm{PK}$ parameters were calculated using proprietary, validated electronic non-compartmental analysis software (eNCA).

\section{Safety assessments}

All observed or volunteered adverse events (AEs), the severity (mild, moderate, or severe) of the events, and the investigator's opinion of the relationship to the study treatment were recorded using the Medical Dictionary for Regulatory Activities terminology (MedDRA; version 15.0). AEs included adverse drug reactions, illnesses with onset during the study, and exacerbation of previous illnesses. Other safety evaluations included any clinically significant changes in physical examination findings, vital signs (BP, heart rate, and respiratory rate), and abnormal test findings (e.g., ECG, laboratory).

\section{Statistical analyses}

A sample size of 14 participants provided $90 \%$ confidence intervals (CIs) for the difference between treatments of $\pm 0.0674, \pm 0.0600$ and \pm 0.1462 on the natural logarithmic scale for oxycodone AUC $\mathrm{AUC}_{\text {last }}$, and $\mathrm{C}_{\max }$, respectively, with $80 \%$ coverage probability. These calculations were based on estimates of within-subject standard deviations of $0.0872,0.0776$, and 0.1891 for $\log _{e} \mathrm{AUC}_{\text {inf }} \mathrm{AUC}_{\text {last' }}$ and $\mathrm{C}_{\max }$, respectively, as obtained from previous studies (Sponsor identifiers ALO-02-09-1001 and B4531003 [10]).

The PK concentration population was defined as all enrolled participants treated who had at least one concentration recorded. The PK parameter analysis population was defined as all enrolled participants treated who had at least one of the PK parameters of interest had recorded.

Natural log-transformed values for dn PK parameters of interest (i.e., oxycodone $\mathrm{C}_{\max }[\mathrm{dn}], \mathrm{AUC}_{\text {last }}[\mathrm{dn}]$, and $\mathrm{AUC}_{\text {inf }}[\mathrm{dn}]$ ) were analyzed using a mixed-effect model with sequence, period, and treatment as fixed effects and subject within sequence as a random effect. Estimates of the adjusted mean differences between the test (ALO-02 $40 \mathrm{mg}$ capsules) and reference (IRO $20 \mathrm{mg}$ tablets) formulations and corresponding $90 \%$ CIs were obtained from the model. The adjusted mean differences and $90 \%$ CIs for the differences were exponentiated to provide estimates of the ratio of adjusted geometric means (ALO-02/ IRO) and $90 \%$ CIs for the ratios. Relative bioavailability was estimated as the ratio of adjusted geometric means for ALO-02 relative to IRO for $\mathrm{AUC}_{\text {inf }}(\mathrm{dn}), \mathrm{AUC}_{\text {last }}(\mathrm{dn})$ and $\mathrm{C}_{\text {max }}(\mathrm{dn})$.

Safety data were presented in listings and summarized descriptively, where appropriate. All participants who received at least one dose of study medication were included in the safety population.

\section{Results}

\section{Study population}

A total of 14 participants were treated and 13 completed the study. Study participants $(n=14)$ had a mean age of 38.1 years (range, 26-51 years) and were mostly male $(n=9,64 \%)$. Half of the participants were black ( $n=7)$, two participants were white, and five were other. The study participants had a mean height of $170.7 \mathrm{~cm}$ (range, 157-182 cm); a mean weight of $73.8 \mathrm{~kg}$ (range, $53.2-89.8 \mathrm{~kg}$ ); and a mean BMI of 25.4 $\mathrm{kg} / \mathrm{m}^{2}$ (range, $19.7-30.1 \mathrm{~kg} / \mathrm{m}^{2}$ ).

One participant treated with IRO $20 \mathrm{mg}$ discontinued from the study prior to receiving ALO-02 $40 \mathrm{mg}$. At approximately 2 hours after receiving IRO $20 \mathrm{mg}$, this participant experienced an AE of gastroenteritis, which was mild and deemed not related to study drug, as well as dizziness and headache, which were both mild in severity. Another participant treated with IRO $20 \mathrm{mg}$ was deemed an influential statistical outlier, with studentized (conditional) residual $<-3$ for $\mathrm{C}_{\text {max }}$ as well as $\mathrm{AUC}_{\mathrm{inf}}$, therefore, $\mathrm{PK}$ results following IRO treatment for this outlier subject were excluded from the summary statistics and analyses. 
Citation: Malhotra B, Matschke K, Bramson C, Wang Q, Salageanu J (2014) Relative Bioavailability Study of an Abuse-Deterrent Formulation of Extended-Release Oxycodone with Sequestered Naltrexone (ALO-02) Versus Immediate-Release Oxycodone Tablets in Healthy Volunteers. J Bioequiv Availab 6: 186-191. doi:10.4172/jbb.1000202

\section{Pharmacokinetic results}

Median plasma oxycodone concentration-time profiles for both treatments are presented in Figure 1 and PK parameters in Table 1. Following administration of single oral doses of ALO-02 $40 \mathrm{mg}$ capsules under fasted conditions, oral absorption of oxycodone was consistent with that of an ER formulation with a slow initial oxycodone release and a prolonged median $\mathrm{T}_{\text {max }}$ of 12 , hours compared with a median $\mathrm{T}_{\max }$ of 1 hour following administration of IRO $20 \mathrm{mg}$ (Figure 1 and Table 1).

The relative oxycodone bioavailability of ALO-02 $40 \mathrm{mg}$ capsules was estimated to be $107.2 \%$ and $106.1 \%$ compared with IRO $20 \mathrm{mg}$ tablets, based on $\mathrm{AUC}_{\text {inf }}(\mathrm{dn})$ and $\mathrm{AUC}_{\text {last }}(\mathrm{dn})$ ratios, respectively, with $90 \%$ CIs within $80 \%-125 \%$ for both (Table 2 and Figure 2). Consistent with the PK profile of the ER ALO-02 formulation, oxycodone $\mathrm{C}_{\max }(\mathrm{dn})$ was lower for the ALO-02 treatment than that observed for the IRO treatment, with ALO-02/IRO adjusted geometric mean ratio (90\% CI) of $33.0 \%(28.8 \%, 37.9 \%)$ (Table 2 and Figure 2$)$.

Plasma naltrexone concentrations for ALO-02 $40 \mathrm{mg}$ treatment were BLQ $(4.00 \mathrm{pg} / \mathrm{mL})$ for all participants and therefore PK parameters were not calculated. Overall plasma $6-\beta$-naltrexol concentrations for ALO-02 $40 \mathrm{mg}$ treatment were low, with more than $50 \%$ of participants having concentration levels BLQ $(4.00 \mathrm{pg} / \mathrm{mL})$. As expected, the overall plasma concentrations for 6- $\beta$-naltrexol were low, with individual $\mathrm{C}_{\max }$ ranging between $0 \mathrm{pg} / \mathrm{mL}$ and $45.4 \mathrm{pg} / \mathrm{mL}$ and were achieved within 96-120 hours post dose (median $\mathrm{T}_{\max }=108$ hours). $\mathrm{AUC}_{\text {inf }}, \mathrm{AUC}_{\text {last }}$ and

\section{A}

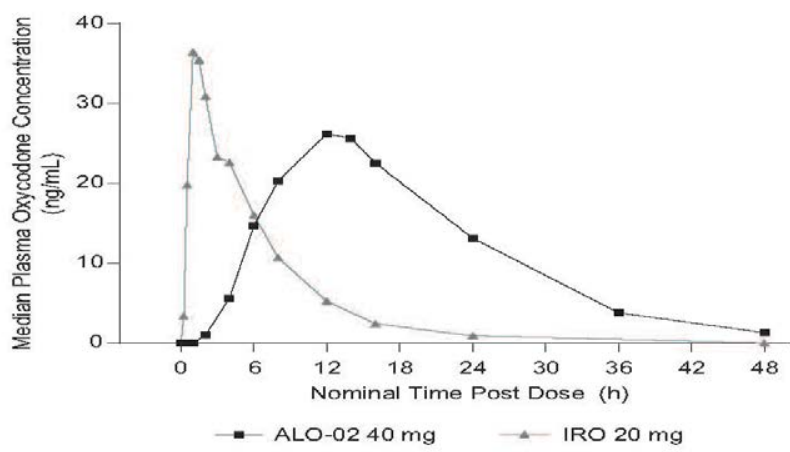

$\mathrm{B}$

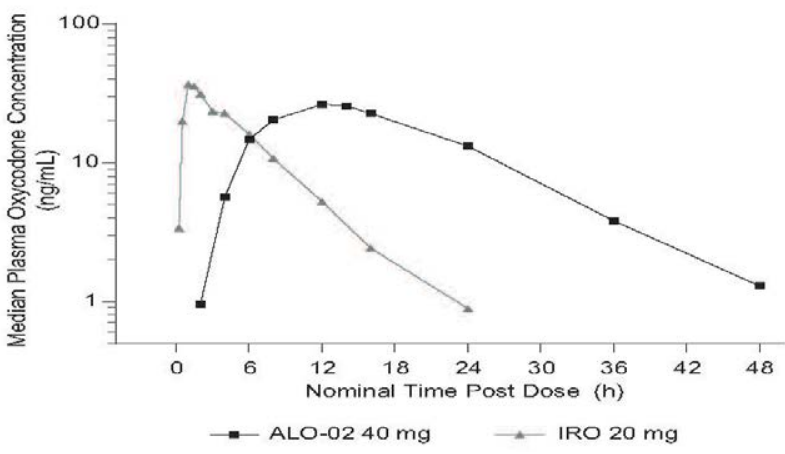

Upper and lower panels are linear and semi-logarithmic scales, respectively. ALO-02: extended-release oxycodone hydrochloride with sequestered naltrexone hydrochloride: IRO: immediate-release oxycodone.

Figure 1: Median plasma oxycodone concentration-time profiles following single oral doses of ALO-02 $40 \mathrm{mg}$ capsules and IRO $20 \mathrm{mg}$ tablets. $t_{1 / 2}$ for 6- $\beta$-naltrexol could not be calculated or accurately reported for any participant treated with ALO-02 $40 \mathrm{mg}$.

\section{Safety}

There were no serious AEs, deaths, temporary discontinuations, or dose reductions due to AEs during this study. One participant treated with IRO $20 \mathrm{mg}$ discontinued from the study due to an $\mathrm{AE}$ that was considered unrelated to study drug (aforementioned). Eight participants reported 38 AEs during treatment with ALO-02 40 $\mathrm{mg}$ and 14 participants reported 54 AEs during treatment with IRO $20 \mathrm{mg}$. All of the events were considered to be mild or moderate in severity, with no severe AEs being reported. The majority of the AEs reported were considered to be treatment-related. The most frequently reported AEs were nausea and dizziness, both of which were reported by five participants treated with ALO- $0240 \mathrm{mg}$ and seven participants treated with IRO $20 \mathrm{mg}$. Treatment-emergent AEs (all causalities and treatment-related) reported by two or more participants receiving any treatment are summarized in Table 3.

Four participants had laboratory abnormalities; of those, three had mild abnormalities in urinalysis results. The fourth participant had abnormalities in gamma-glutamyl transferase (GGT) and alanine aminotransferase (ALT) $>3.0 \times$ upper limit of normal (ULN) on Day 7

\begin{tabular}{|c|c|c|}
\hline \multirow{2}{*}{ Parameter, Units } & \multicolumn{2}{|c|}{$\begin{array}{c}\text { Parameter Summary Statistics } \\
\text { by Treatment }\end{array}$} \\
\hline & ALO-02 $40 \mathrm{mg}$ & IRO $20 \mathrm{mg}$ \\
\hline No. of participants & 13 & 13 \\
\hline $\mathrm{AUC}_{\text {inf }}, \mathrm{ng} \cdot \mathrm{h} / \mathrm{mL}$ & $508.8(29)$ & $238.8(23)$ \\
\hline $\mathrm{AUC}_{\text {inf }}(\mathrm{dn}), \mathrm{ng} \cdot \mathrm{h} / \mathrm{mL} / \mathrm{mg}$ & $12.71(29)$ & $11.93(23)$ \\
\hline $\mathrm{AUC}_{\text {last}}, \mathrm{ng} \cdot \mathrm{h} / \mathrm{mL}$ & $496.2(29)$ & $235.5(23)$ \\
\hline $\mathrm{AUC}_{\text {last }}(\mathrm{dn}), \mathrm{ng} \cdot \mathrm{h} / \mathrm{mL} / \mathrm{mg}$ & $12.41(29)$ & $11.78(23)$ \\
\hline $\mathrm{C}_{24}, \mathrm{ng} / \mathrm{mL}$ & $11.57(37)$ & $0.69(61)$ \\
\hline $\mathrm{C}_{\max }, \mathrm{ng} / \mathrm{mL}$ & $26.57(24)$ & $40.12(25)$ \\
\hline $\mathrm{C}_{\max }(\mathrm{dn}), \mathrm{ng} / \mathrm{mL} / \mathrm{mg}$ & $0.66(24)$ & $2.01(25)$ \\
\hline $\mathrm{T}_{\text {max }}, \mathrm{h}$ & $12.0(8.0-16.0)$ & $1.0(0.5-2.0)$ \\
\hline $\mathrm{t}_{1 / 2}, \mathrm{~h}$ & $7.21 \pm 0.96$ & $4.58 \pm 1.20$ \\
\hline
\end{tabular}

ALO-02: extended-release oxycodone hydrochloride with sequestered naltrexone hydrochloride; $A \cup C_{\text {in: }}$ : area under the curve from time zero extrapolated to infinity; AUC : area under the curve from time zero to the time of the last quantifiable concentration; $\mathrm{C}_{24}$ : concentration at 24 hours post dose; $\mathrm{C}_{\max }$ : maximum plasma concentration; CV: coefficient of variation; dn: dose-normalized to $1 \mathrm{mg}$; IRO immediate-release oxycodone; $\mathrm{N}$ : total number of participants in the treatment group and contributing to the mean; $S D$ : standard deviation; $\mathrm{t}_{1 / 2}$ : terminal half-life; $\mathrm{T}_{\max }:$ time to reach maximum concentration.

1 Geometric mean (geometric \% coefficient of variation) for all except: median (range) for $\mathrm{T}_{\max }$ and arithmetic mean $\pm \mathrm{SD}$ for $\mathrm{t}_{1 / 2}$.

Table 1: Plasma oxycodone pharmacokinetic parameters following single oral doses of ALO-02 $40 \mathrm{mg}$ capsules and IRO $20 \mathrm{mg}$ tablets.

\begin{tabular}{|c|c|c|c|c|}
\hline \multirow{2}{*}{ Parameter, Units } & \multicolumn{2}{|c|}{ Adjusted Geometric Means } & \multirow{2}{*}{$\begin{array}{c}\text { Ratio (\%) } \\
\text { ALO-02/IRO }\end{array}$} & \multirow{2}{*}{$\begin{array}{l}90 \% \mathrm{Cl} \text { for } \\
\text { Ratio (\%) }\end{array}$} \\
\hline & ALO-02 $40 \mathrm{mg}$ & IRO $20 \mathrm{mg}$ & & \\
\hline $\begin{array}{c}\mathrm{AUC}_{\mathrm{inf}}(\mathrm{dn}), \mathrm{ng} \cdot \mathrm{h} / \\
\mathrm{mL} / \mathrm{mg}\end{array}$ & 12.75 & 11.90 & 107.2 & $(96.7,118.8)$ \\
\hline $\begin{array}{c}\mathrm{AUC}_{\text {last }}(\mathrm{dn}), \mathrm{ng} \cdot \mathrm{h} / \\
\mathrm{mL} / \mathrm{mg}\end{array}$ & 12.45 & 11.74 & 106.1 & $(95.35,118.0)$ \\
\hline $\mathrm{C}_{\max }(\mathrm{dn}), \mathrm{ng} / \mathrm{mL} / \mathrm{mg}$ & 0.67 & 2.03 & 33.0 & $(28.80,37.9)$ \\
\hline
\end{tabular}

ALO-02: extended-release oxycodone hydrochloride with sequestered naltrexone hydrochloride; $A \cup C_{\text {in: }}$ : area under the curve from time zero extrapolated to infinity; AUC : area under the curve from time zero to the time of the last quantifiable concentration; $\mathrm{Cl}$ : confidence interval; $\mathrm{C}_{\max }$ : maximum plasma concentration; $\mathrm{dn}$ : dose-normalized to $1 \mathrm{mg}$; IRO: immediate-release oxycodone.

Table 2: Statistical summary of treatment comparisons for dose-normalized plasma oxycodone pharmacokinetic parameters following single oral doses of ALO-02 40 $\mathrm{mg}$ capsules and IRO $20 \mathrm{mg}$ tablets. 
Citation: Malhotra B, Matschke K, Bramson C, Wang Q, Salageanu J (2014) Relative Bioavailability Study of an Abuse-Deterrent Formulation of Extended-Release Oxycodone with Sequestered Naltrexone (ALO-02) Versus Immediate-Release Oxycodone Tablets in Healthy Volunteers. J Bioequiv Availab 6: 186-191. doi:10.4172/jbb.1000202
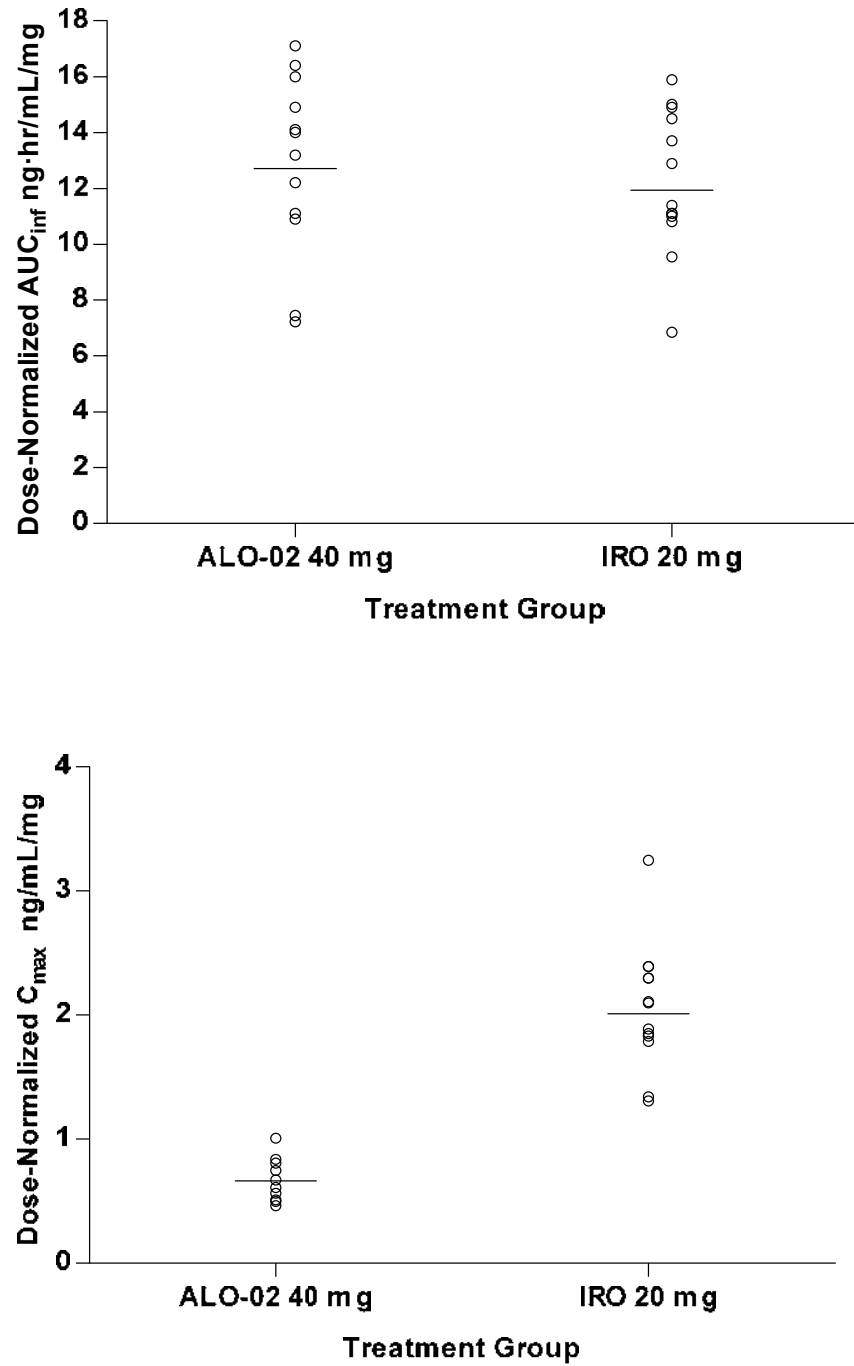

Circle identifies individual participant value and line identifies geometric means.

ALO-02: extended-release oxycodone hydrochloride with sequestered naltrexone hydrochloride; $A \cup C_{\text {inf: }}$ area under the plasma concentrationtime profile from time 0 extrapolated to infinity; $C_{\max }$ : maximum plasma concentration; IRO: immediate-release oxycodone.

Figure 2: Individual and geometric mean dose-normalized plasma oxycodone AUC (upper panel) and $C_{\text {max }}$ (lower panel) values by treatment following single oral doses of ALO-02 $40 \mathrm{mg}$ capsules and IRO $20 \mathrm{mg}$ tablets.

after treatment with IRO $20 \mathrm{mg}$. The ALT had returned to normal on Day 13 and the GGT declined from the peak value, but remained above normal on the day that it was last assessed (Day 11). This participant also had an alkaline phosphatase level that was elevated slightly above ULN on Day 7 and returned to normal on Day 22. None of the laboratory abnormalities were considered clinically significant or reported as AEs. None of the vital signs or ECG results were abnormal.

\section{Discussion}

ALO-02 is a proprietary ER dosage form, designed to release therapeutic amounts of oxycodone from controlled-release pellets in an ER manner while sequestering the naltrexone in the pellets unless the pellets are crushed, chewed, or otherwise disrupted. In this study, participants were instructed to swallow the study medication intact and not to chew the medication prior to swallowing. As expected, there were no quantifiable plasma concentrations $(>4.00 \mathrm{pg} / \mathrm{mL})$ of naltrexone in any of the treatments administered. For 6 - $\beta$-naltrexol, plasma concentrations were low $(<30 \mathrm{pg} / \mathrm{mL})$, with less than $50 \%$ of participants in the ALO-02 treatment having quantifiable plasma concentrations above the low limit of quantitation $(>4.00 \mathrm{pg} / \mathrm{mL})$. These results indicate that naltrexone was successfully sequestered in the capsules when ALO-02 was administered intact as intended.

The PK profile of oxycodone following single oral doses of ALO-02 $40 \mathrm{mg}$ capsules was characterized by a substantially slower absorptive phase than following IRO $20 \mathrm{mg}$ tablets, represented by a delayed time-to-peak oxycodone concentration and substantially lower oxycodone peak concentration. Consistent with the PK profile of the ER formulation, oxycodone mean $\mathrm{C}_{\max }$ was approximately 67\% lower following ALO-02 treatment than that observed following IRO treatment. Despite the ER, there was no reduction in oxycodone bioavailability from ALO-02 based on dose-normalized $\mathrm{AUC}_{\text {inf }}$ or $\mathrm{AUC}_{\text {last }}$ when compared with IRO formulation.

When viewed in light of the reference treatment, the PK characteristics of ALO-02 at a clinically relevant dose of $40 \mathrm{mg}$, demonstrating a similar overall drug exposure based on AUCs, but with a longer $\mathrm{t}_{1 / 2}$, extended $\mathrm{T}_{\max }$, reduced $\mathrm{C}_{\max }$, and higher $\mathrm{C}_{24}$ concentrations support the use of ALO-02 for twice-daily treatment of pain that requires around-the-clock analgesia. The abuse-deterrent formulation of ALO-02 was also shown to keep naltrexone successfully sequestered while delivering oxycodone with a controlled release such that a risk of withdrawal is minimized in opioid-dependent patients, when ALO-02 is used as intended, without chewing or crushing.

\begin{tabular}{|c|c|c|}
\hline $\begin{array}{l}\text { Number of participants with AEs } \\
\text { by system organ class } \\
\text { MedDRA Preferred Term }{ }^{1}\end{array}$ & $\begin{array}{c}\text { ALO-02 } 40 \mathrm{mg} \\
\mathrm{n}=13\end{array}$ & $\begin{array}{c}\text { IRO } 20 \mathrm{mg} \\
\mathrm{n}=14\end{array}$ \\
\hline Gastrointestinal disorder & $6(6)$ & $7(7)$ \\
\hline Abdominal pain & $1(1)$ & $2(1)$ \\
\hline Constipation & $2(2)$ & $2(2)$ \\
\hline Nausea & $5(5)$ & $7(7)$ \\
\hline Vomiting & $5(5)$ & $2(2)$ \\
\hline $\begin{array}{l}\text { General disorder and administration site } \\
\text { conditions }\end{array}$ & $2(2)$ & $4(3)$ \\
\hline Fatigue & $2(2)$ & 0 \\
\hline Feeling abnormal & 0 & $2(2)$ \\
\hline Nervous system disorders & $7(7)$ & $11(10)$ \\
\hline Dizziness & $5(5)$ & $7(6)$ \\
\hline Headache & $3(3)$ & $4(3)$ \\
\hline Somnolence & $3(3)$ & $5(5)$ \\
\hline Psychiatric disorders & $2(2)$ & $5(5)$ \\
\hline Euphoric mood & 0 & $5(5)$ \\
\hline $\begin{array}{l}\text { Respiratory, thoracic, and mediastinal } \\
\text { disorders }\end{array}$ & 0 & $2(2)$ \\
\hline Dyspnea & 0 & $2(2)$ \\
\hline Skin and subcutaneous tissue disorders & $2(2)$ & $5(3)$ \\
\hline Ecchymosis & $2(1)$ & $2(0)$ \\
\hline Pruritus & $1(1)$ & $2(2)$ \\
\hline
\end{tabular}

AE: adverse event; ALO-02: extended-release oxycodone hydrochloride with sequestered naltrexone hydrochloride; IRO: immediate-release oxycodone. ${ }^{1}$ Medical Dictionary for Regulatory Activities terminology (MedDRA; version 15.0) was applied.

Table 3: Incidence of treatment-emergent AEs in at least two participants by treatment; all causalities (treatment-related). 
Citation: Malhotra B, Matschke K, Bramson C, Wang Q, Salageanu J (2014) Relative Bioavailability Study of an Abuse-Deterrent Formulation of Extended-Release Oxycodone with Sequestered Naltrexone (ALO-02) Versus Immediate-Release Oxycodone Tablets in Healthy Volunteers. J Bioequiv Availab 6: 186-191. doi:10.4172/jbb.1000202

Single oral doses of ALO-02 $40 \mathrm{mg}$ capsules and IRO $20 \mathrm{mg}$ tablets were generally well tolerated. There were no severe AEs, serious AEs, deaths, discontinuations, dose reductions, or temporary discontinuations due to AEs during this study. One participant discontinued from the study due to a mild $\mathrm{AE}$ of gastroenteritis unrelated to study treatment. The majority of AEs were mild in severity, and the most frequently reported AEs (nausea and dizziness) were typical of oxycodone and other opioids [11]. None of the vital signs or ECG results were abnormal, and no laboratory abnormalities were considered clinically significant or reported as AEs.

The results of this study should be viewed against its limitations. This was a small study with 14 healthy volunteers, a sample size adequate for relative bioavailability assessment while not powered for establishing equivalence of AUC.

\section{Conclusions}

Comparison of AUC values following ALO-02 $40 \mathrm{mg}$ versus IRO $20 \mathrm{mg}$ indicates equivalent oxycodone bioavailability under fasted conditions. The approximately $67 \%$ lower $\mathrm{dn} \mathrm{C}_{\max }$, median $\mathrm{T}_{\max }$ delay by approximately 11 hours, and prolonged $t_{1 / 2}$ by approximately 2.6 hours for ALO-02 versus IRO are consistent with the ER formulation characteristics of ALO-02. Plasma naltrexone and 6- $\beta$-naltrexol concentrations were generally either BLQ or very low, indicating successful sequestration of naltrexone in ALO-02. Single doses of ALO-02 $40 \mathrm{mg}$ were generally well tolerated, and the most common AEs were typical of opioids.

\section{Acknowledgements}

This study was sponsored by Pfizer Inc. All authors are full-time employees and shareholders of Pfizer Inc. Medical writing support was provided by Vardit Dror, $\mathrm{PhD}$, of Engage Scientific Solutions and funded by Pfizer Inc.

\section{References}

1. Chou R (2009) Clinical Guidelines from the American Pain Society and the American Academy of Pain Medicine on the use of chronic opioid therapy in chronic noncancer pain: what are the key messages for clinical practice? Pol Arch Med Wewn 119: 469-477.

2. Sachs CJ (2005) Oral analgesics for acute nonspecific pain. Am Fam Physician 71: $913-918$

3. US Food and Drug Administration. FDA announces safety labeling change and post market study requirement for extended-release and long-acting opioid analgesics (2013).

4. Centers for Disease Control and Prevention (2011) Vital signs: overdoses of prescription opioid pain relievers---United States, 1999--2008. MMWR Morb Mortal Wkly Rep 60: 1487-1492.

5. Paulozzi LJ, Weisler RH, Patkar AA (2011) A national epidemic of unintentional prescription opioid overdose deaths: how physicians can help control it. J Clin Psychiatry 72: 589-592

6. Substance Abuse and Mental Health Services Administration. The DAWN report: trends in emergency department visits involving nonmedical use of narcotic pain relievers.

7. Center for Drug Evaluation and Research. Guidance for industry: abusedeterrent opioids - evaluation and labeling: draft guidance.

8. Butler SF, Budman SH, Licari A, Cassidy TA, Lioy K, et al. (2008) National addictions vigilance intervention and prevention program (NAVIPPRO): a realtime, product-specific, public health surveillance system for monitoring prescription drug abuse. Pharmacoepidemiol Drug Saf 17: 1142-1154.

9. Katz N, Dart RC, Bailey E, Trudeau J, Osgood E, et al. (2011) Tampering with prescription opioids: nature and extent of the problem, health consequences, and solutions. Am J Drug Alcohol Abuse 37: 205-217.

10. Gandelman K, Lamson M, Salageanu J, Bramson C, Matschke K, et al. (2014) Evaluation of the effects of food and of sprinkling pellets on applesauce on the pharmacokinetics of oxycodone and naltrexone from ALO-02, an extended release formulation of oxycodone with sequestered naltrexone. J Clin Pharm Ther [in press].

11. Coluzzi F, Mattia C (2005) Oxycodone. Pharmacological profile and clinical data in chronic pain management. Minerva Anestesiol 71: 451-460. 